\title{
EFEKTIFITAS SENAM HAMIL TERHADAP KUALITAS TIDUR PADA IBU HAMIL TRIMESTER III DI KLINIK PRATAMA ARRABIH PEKANBARU
}

\author{
Rita Afni, Octa Dwienda Ristica \\ STIKes Hang Tuah Pekanbaru
}

\begin{abstract}
Difficulty sleeping in pregnant women can usually occur from mid-pregnancy to the end of pregnancy. Difficulty sleeping can be caused by physical changes, namely the enlargement of the uterus. In addition, difficulty sleeping can also be caused by psychological changes such as feelings of fear, anxiety or worry because of facing birth. The result of poor sleep quality can be at risk for pregnancy and during childbirth (Rahayu \& Hastuti, 2019). The role of midwives in helping mothers reduce complaints of difficulty sleeping, namely by suggesting finding a comfortable sleeping position, or pregnant women can also overcome difficulty sleeping with exercise. Sports intended for pregnant women are sports that are safe for their pregnancy. The type of exercise that is most suitable for pregnant women is pregnancy exercise (Mediarti et al., 2014). This study aims to determine the effectiveness of Pregnancy Exercise on Sleep Quality in Third Trimester Pregnant Women at the Arrabih Pratama Clinic, Pekanbaru.

This type of research is a quantitative study with a Quasi Experimental design using pretest and posttest to determine how the relationship between Pregnancy Exercise and Sleep Quality, the results of which are measured before and after pregnancy exercise.

The results showed that there was a relationship between pregnancy exercise and the quality of mother's sleep and the results of statistical tests showed that the correlation between the two variables was 0.000 , which means that the correlation was very significant because it was close to 1 , namely the $\rho$ value was $0.000<0.05$.
\end{abstract}

Keywords: effectiveness, pregnancy exercise, sleep quality

Abstrak

Sulit tidur pada ibu hamil ini biasanya dapat terjadi mulai pada pertengahan masa kehamilan sampai akhir kehamilan. Sulit tidur dapat disebabkan oleh perubahan fisik yaitu pembesaran uterus. Di samping itu sulit tidur dapat juga disebabkan perubahan psikologis misalnya perasaan takut, gelisah atau khawatir karena menghadapi kelahiran. Akibat dari kurang baiknya kualitas tidur bisa berisiko terhadap kehamilan dan saat proses melahirkan (Rahayu \& Hastuti, 2019). Adapun peran bidan dalam membantu ibu mengurangi keluhan sulit tidur yaitu dengan menyarankan untuk mencari posisi tidur yang nyaman, atau ibu hamil juga bisa mengatasi sulit tidur dengan olahraga.Olahraga yang diperuntukkan bagi ibu hamil adalah olahraga yang aman bagi kehamilannya. Jenis olahraga yang paling sesuai untuk ibu hamil adalah senam hamil (Mediarti et al., 2014).

Penelitian ini bertujuan untuk mengetahui efektif Senam Hamil Terhadap Kualitas Tidur pada Ibu Hamil Trimester III di Klinik Pratama Arrabih Pekanbaru.

Jenis penelitian ini adalah penelitian kuantitatif dengan desain Quasi Eksperimen dengan menggunakan pretest dan posttest untuk mengetahui bagaimana hubungan Senam Hamil Terhadap Kualitas Tidur yang hasil ukurnya dilakukan sebelum dan setelah dilakukan senam hamil.

Hasil penelitian didapatkan ada hubungan senam hamil terhadap kualitas tidur ibu dan hasil uji statistik menunjukkan besar korelasi antara kedua variabel adalah 0,000 artinya korelasi sangat signifikan karena mendekati 1 yaitu $\rho$ value adalah $0,000<0,05$.

Kata kunci: Efektifitas, senam hamil, Kualitas Tidur 


\section{PENDAHULUAN}

Kehamilan adalah fertilisasi atau penyatuan dari spermatozoa dan ovum dan dilanjutkan dengan nidasi atau implantasi. Bila dihitung dari saat fertilisasi hingga lahirnya bayi, kehamilan normal akan berlangsung dalam waktu 40 minggu atau 9 bulan menurut kalender internasioal. Kehamilan terbagi dalam 3 trimester, dimana trimester kesatu berlangsung dalam 12 minggu, trimester kedua 15 minggu (minggu ke-13 hingga ke-27), dan trimester ketiga 13 minggu (minggu ke-28 hingga ke-40) (Prawirohardjo, 2010).

Ibu hamil pada trimester III merasakan ketidaknyamanan yang lebih banyak karena semakin dekat dengan waktu melahirkan. Ibu hamil harus dipersiapkan untuk beradaptasi terhadap ketidaknyamanan yang dirasakan dan perlu juga menghindari faktor-faktor yang dapat mempengaruhi kehamilan supaya kehamilan berjalan lancar dan dapat melahirkan dengan sehat baik ibu maupun bayinya. Sering kita temui ibu hamil trimester III datang ke fasilitas pelayanan kesehatan dengan berbagai keluhan seperti malam hari kaki kram, sering BAK, sulit tidur, oedema, sakit pinggang dan masih banyak keluhan yang lain (Tyastuti \& Wahyuningsih, 2016).

Sulit tidur pada ibu hamil ini biasanya dapat terjadi mulai pada pertengahan masa kehamilan sampai akhir kehamilan. Sulit tidur dapat disebabkan oleh perubahan fisik yaitu pembesaran uterus. Di samping itu sulit tidur dapat juga disebabkan perubahan psikologis misalnya perasaan takut, gelisah atau khawatir karena menghadapi kelahiran. Sering BAK dimalam hari dapat juga menjadi penyebab terjadinya gangguan tidur pada ibu hamil. Akibat dari kurang baiknya kualitas tidur bisa berisiko terhadap kehamilan dan saat proses melahirkan (Rahayu \& Hastuti, 2019).

Kebutuhan istirahat apabila belum terpenuhi akan berpengaruh terhadap kesehatan janin. Ibu hamil memerlukan sekitar delapan jam untuk tidur dimalam hari, selain itu tidur siang juga dibutuhkan oleh ibu hamil. Ketika memasuki trimester III semakin banyak keluhan-keluhan yang dirasakan ibu sehingga menggangu istirahat dan tidur (Palifiana \& Wulandari, 2018).

$$
\text { Menurut Husin F, (2014) }
$$
menyampaikan bahwa dalam penelitian terbaru yang dilakukan oleh National Sleep Foundation menyatakan bahwa lebih dari $79 \%$ wanita hamil mengalami gangguan dalam tidurnya. Sering lelah dan gangguan tidur adalah salah satu keluhan yang paling sering disampaikan oleh ibu hamil. Rata-rata $60 \%$ dari ibu hamil merasakan sering lelah pada akhir semester dan lebih dari $75 \%$ mengeluhkan gangguan pola tidur. 
Adapun peran bidan dalam membantu ibu mengurangi keluhan sulit tidur yaitu dengan menyarankan untuk mencari posisi tidur yang nyaman,mandi air hangat sebelum tidur,mendengarkan music klasik,minum segelas air susu hangat atau ibu hamil juga bisa mengatasi sulit tidur dengan olahraga.Olahraga yang diperuntukkan bagi ibu hamil adalah olahraga yang aman bagi kehamilannya. Jenis olahraga yang paling sesuai untuk ibu hamil adalah senam hamil (Mediarti et al., 2014).

Senam hamil merupakan suatu bentuk olahraga atau latihan yang terstruktur. Senam hamil sebagai salah satu alternatif dan pelayanan prenatal yang dapat memutuskan siklus kecemasan dan meningkatkan rasa nyaman ibu hamil ketika tidur ataupun untuk mengurangi keluhan-keluhan ibu hamil yang mengakibatkan penurunan durasi tidur ibu hamil (Wahyuni \& Ni'mah, 2013).

Dari hasil penelitian lain yang dilakukan oleh (Rahayu \& Hastuti, 2019) menyimpulkan bahwa senam hamil berpengaruh dalam mengatasi masalah gangguan tidur yakni dengan meningkatkan kualitas tidur pada ibu hamil trimester III atau menjelang persalinan. Hasil penelitian tersebut menunjukkan bahwa senam hamil sangat membantu mengatasi gangguan tidur ibu selama kehamilan melalui gerakangerakan dan latihan pernafasan dalam senam hamil. Salah satu manfaat senam hamil diantaranya yakni untuk meningkatkan durasi tidur ibu hamil. Bila ibu hamil melakukan latihan tersebut dengan rutin dan benar akan terasa efek relaksasi pada ibu hamil yang berguna untuk mengatasi kecemasan dan ketegangan (Wahyuni \& Ni'mah, 2013).

Berdasarkan survey yang dilakukan di Klinik Pratama Arrabih dari 10 orang ibu hamil 7 diantaranya mengalami sulit tidur di trimester III, ibu mengatakan sering merasakan gangguan dalam tidur akibat peningkatan frekuensi buang air kecil, kram perut, sakit pinggang serta mengalami kecemasan, rasa takut, khawatir akan kehamilan dan proses persalinan. Mengingat pentingnya manfaat senam hamil sebagai salah satu alternative untuk mengurangi keluhan-keluhan ibu hamil yang mengakibatkan kualitas tidur menurun.

\section{METODE PENELITIAN}

Metode penelitian ini menggunakan Jenis penelitian yang dilakukan adalah Quasi experimental (experiment semu) dengan Rancangan pendekatan one group pretest posttest. Populasi dalam penelitian ini adalah ibu hamil di Klinik Pratama Arrabih Pekanbaru dari Oktober 2019 - Desember 2019. Sampel pada penelitian ini ibu Hamil Trimester III di Klinik Pratama Arrabih Pekanbaru sebanyak 35 responden. Pengambilan data menggunakan data primer dengan metode penelususran secara langsung terhadap responden dengan meneliti kualitas tidur ibu hamil di Klinik Pratama Arrabih Pekanbaru. Pengolahan data dilakukan dengan cara univariat dan bivariat. 


\section{HASIL}

Dari hasil penelitian yang telah dilakukan, didapatkan hasil bahwa rata-rata kualitas tidur pada ibu hamil Trimester III pada pengukuran pertama adalah 5.63 (Kualitas buruk), sedangkan rata-rata kualitas tidur pada ibu hamil Trimester III pada pengukuran kedua adalah 4,90 (kualitas baik)

Pada test statistik, diperoleh nilai $\mathrm{p}=$ 0,000 sehingga Ho ditolak maka disimpulkan ada pengaruh senam hamil terhadap kualitas tidur ibu hamil trimester III $(\mathrm{p}<0,000)$.

\begin{tabular}{|c|c|c|c|c|c|}
\hline & $\mathrm{N}$ & Mean & $\begin{array}{l}\text { Std. } \\
\text { Deviation }\end{array}$ & $\begin{array}{l}\text { Std.error } \\
\text { mean }\end{array}$ & $\begin{array}{l}\text { P.Val } \\
\text { ue }\end{array}$ \\
\hline $\begin{array}{l}\text { Sebelum } \\
\text { diberikan }\end{array}$ & & 5.63 & 1.653 & 0.301 & \\
\hline $\begin{array}{l}\text { Sesudah } \\
\text { diberikan }\end{array}$ & 35 & 4,90 & 1.567 & 0.268 & 0,000 \\
\hline
\end{tabular}

\section{PEMBAHASAN}

Analisa Perbedaan kualitas tidur Sebelum (Pre-Test) Dan Sesudah (PostTest) melakukan senam hamil, didapatkan hasil bahwa rata-rata kualitas tidur pada ibu hamil Trimester III pada pengukuran pertama adalah 5.63 (Kualitas buruk), sedangkan ratarata kualitas tidur pada ibu hamil Trimester III pada pengukuran kedua adalah 4,90 (kualitas baik). Pada test statistik, diperoleh nilai $\mathrm{p}=0,000$ sehingga Ho ditolak maka disimpulkan ada pengaruh senam hamil terhadap kualitas tidur ibu hamil trimester III $(\mathrm{p}<0,000)$.

Hal ini sesuai dengan teori (Husin F, 2014) yang mengatakan senam hamil secara teratur dapat meningkatkan kualitas tidur dan menguasai teknikteknik pernafasan dan dapat mengatur diri kepada ketenangan. karena senam hamil akan memberikan efek relaksasi pada ibu hamil yang bisa berpengaruh terhadap peningkatan durasi tidur ibu hamil. Latihan relaksasi pada senam hamil secara fisiologis akan menimbulkan efek relaks yang melibatkan syaraf parasimpatis dalam sistem syaraf pusat..Selain itu senam hamil akan membantu ibu dalam kondisi rileks akibat terbentuknya endorphin yang memberikan efek menenangkan. Dengan demikian ibu hamil mudah tidur dengan kualitas yang baik dengan ketentuan senam hamil dilakukan dengan teratur untuk mendapatkan hasil yang lebih optimal.

Secara fisiologis keluhan tidur yang dialami ibu hamil disebabkan oleh pertumbuhan janin dan pergerakan janin yang dapat menekan kandung kemih sehingga dapat meningkatkan frekuensi buang air kecil, beban tubuh yang semakin berat sehingga dapat merubah struktur tulang belakang sehingga ibu hamil dapat merasakan ketidaknyamanan di daerah pinggang, begitu juga di bagian ektremitas yang terkadang ibu hamil suka mengalami kram. Kondisi ini juga dapat menimbulkan perubahan psikologis ibu hamil, yang terkadang perubahan fisik yang dialaminya dapat menimbulkan kecemasan, dan kekhawatiran saat menghadapi persalinan, 
hal ini yang terkadang dapat mempengaruhi kualitas tidur ibu hamil (Hidayat \& Uliyah, 2015).

Upaya yang dilakukan untuk mengatasi masalah pola tidur pada ibu hamil salah satunya adalah dengan melakukan latihan gerak tubuh, relaksasi, dan mengatur pola nafas ibu. Latihan gerak bisa dilakukan dengan menggunakan metode senam hamil.

Latihan relaksasi pada senam hamil secara fsiologis akan menimbulkan efek relaks yang melibatkan syaraf parasimpatis dalam sistem syaraf pusat. Dimana salah satu fungsi syaraf parasimpatis ini adalah menurunkan produksi hormone adrenalin atau epinefrin (hormone stress) dan meningkatkan skresi hormone noradrenalin atau norepinefrin (hormone relaks) sehingga terjadi penurunan kecemasan serta ketegangan pada ibu hamil yang mengakibatkan ibu hamil menjadi lebih relaks dan tenang.Selain itu senam hamil akan membantu ibu dalam kondisi rileks akibat terbentuknya endorphin yang memberikan efek menenangkan. Dengan demikian ibu hamil mudah tidur dengan kualitas yang baik dengan ketentuan senam hamil dilakukan dengan teratur untuk mendapatkan hasil yang lebih optimal. Senam hamil dapat dilakukan 3-4 kali dalam seminggu di pagi atau sore hari dirumah dengan durasi 10-20 menit

\section{SARAN}

Diharapkan kepada penyedia tempat pelayanan asuhan kebidanan yang sedang menjalankan praktik untuk dapat melakukan penyuluhan kepada ibu hamil khususnya dengan sulit tidur pada trimester III agar ketidaknyamanan pada ibu hamil dapat di atasi, dan untuk menyediakan fasilitas-fasilitas yang berhubungan dengan ibu hamil seperti kelas ibu hamil (senam maupun yoga).

\section{DAFTAR PUSTAKA}

Agustin, D. (2012). Faktor-Faktor Yang Mempengaruhi Kualitas Tidur Pada Pekerja Shift Di Pt Krakatau Tirta Industri Cilegon. universita indonesia.

Handayani, S. R. (2017). Dokumentasi Kebidanan. Pusdik SDM Kementrian Kesehatan Republik Indonesia.

Khasanah, K., \& Hidayati, W. (2012). Kualitas Tidur Lansia Balai Rehabilitasi Sosial “ MANDIRI" Semarang. Jurnal Nursing Studies, 1(1), 189-196. http://ejournal-

s1.undip.ac.id/index.php/jnursing

Marwiyah, N., \& Sufi, F. (2018). Pengaruh Senam Hamil Terhadap Kualitas Tidur Ibu Hamil Trimester II dan III di Kelurahan Margaluyu Wilayah Kerja Puskesmas Kasemen. Faletehan Health Journal, $\quad 5(3), \quad$ 123-128. https://doi.org/10.33746/fhj.v5i3.34

Mediarti, D., Sulaiman, Rosnaini, \& Jawiah. (2014). Pengaruh Yoga Antenatal 
Terhadap Pengurangan Keluhan Ibu Hamil Trimester III. Jurnal Kedokteran Dan Kesehatan:Publikasi Ilmiah Fakultas Kedokteran Universitas Sriwijaya, $\quad$ l(1), 47-53. https://ejournal.unsri.ac.id/index.php/jk k/article/view/2567

Palifiana, D. A., \& Wulandari, S. (2018). Hubungan Ketidaknyamanan Dalam Kehamilan Dengan Kualitas Tidur Ibu Hamil Trimester Iii Di Klinik Pratama Asih Waluyo Jati. 31-40. https://dspace.uii.ac.id/handle/1234567 $89 / 11435$

Prawirohardjo, S. (2010). ILMU KEBIDANAN Sarwono Prawirohardjo. PT Bina Pustaka Sarwono. https://drive.google.com/drive/my-drive Rahayu, D. T., \& Hastuti, N. H. (2019). Pengaruh Keteraturan Senam Hamil terhadap Kualitas Tidur pada Ibu Hamil Trimester III di Desa Gedangsewupare Kediri. Jurnal Kebidanan Midwiferia, $4(2), 34-45$.

Siregar, mukhlidah hanun. (2011). Mengenal Sebab-Sebab, Akibat-Akibat, dan Cara Terapi Insomnia. Flash Books.

Utami, A. P. (2015). Hubungan Frekwensi Senam Hamil Dengan Kualitas Tidur Pada Ibu Hamil Di Wilayah Kerja Puskesmas Palang Kabupaten Tuban. Kesehatan, 24-34.
Wahyuni, \& Ni'mah, L. (2013). Manfaat Senam Hamil Untuk Meningkatkan Durasi Tidur Ibu Hamil. Manfaat Senam Hamil Untuk Meningkatkan Durasi Tidur Ibu Hamil, 8(2), 128-136. https://doi.org/10.15294/kemas.v8i2.26 38 